\title{
Restaurant Mobile Application towards Purchase Intention
}

\author{
Stella Nathalia Ignacia ${ }^{1}$, Rachel Dyah Wiastuti ${ }^{1 *}$ and Diena Mutiara Lemy ${ }^{2}$ \\ ${ }^{1}$ Hotel Management Department \\ Faculty of Economics and Communication. Bina Nusantara University \\ Jl. K. H. Syahdan No.9. Palmerah, Jakarta 11480, Indonesia \\ Ph/Fax: +62215345830/ +62215300244 \\ ${ }^{2}$ Hospitality Management. Pelita Harapan School of Hospitality and Tourism \\ Jl. M.H. Thamrin Boulevard 1100, Lippo Vilage, Karawaci, \\ Banten 15811, Indonesia \\ Ph/Fax: +62215460901/ +62215460910 \\ *rwiastuti@binus.edu
}

\begin{abstract}
The fast development of mobile applications has widely impact many industries including tourism. Restaurant as one of tourism product must then adapt to this new technology because it will benefit more than mobile web. Domino's Pizza Indonesia is the first fast food restaurant in Indonesia that launched its mobile application in 2015 and keeps gaining its popularity. The purpose of this research is to identify the Domino's Pizza Indonesia Mobile Application quality rating and to determine the extent of Domino's Pizza Indonesia Mobile Application towards purchase intention. This research is using quantitative method. Primary data were collected from Domino's Pizza Indonesia mobile application and survey using questionnaire. A survey was conducted for 76 respondents using simple random sampling method. Data was analyzed using Mobile Application Rating Scale (MARS) as guidelines that consist of four objectives quality scales; engagement, functionality, aesthetics and information quality; and one subjective quality scales. The results indicate that Domino's Pizza Indonesia Mobile Application quality considered as good, but assess differently between apps- user and non apps- user. Apps- user assesses information quality as the highest scale while non apps-user assesses functionality quality; with both assess engagement quality as the lowest scale. This research reveals that branded mobile application has strong relationship with purchase intention, despite whether people install the mobile application or not. However, purchase intention is likely influenced more by branded mobile application non appsuser rather than the apps- user itself. Implication of this study provides recommendations for restaurant business to always maintain and enhance the mobile application quality that are expected to be in line with the growth of restaurant revenue.
\end{abstract}

Keywords: Restaurant mobile apps; Mobile application; Domino's apps; Purchase intention; Mobile apps

\section{Introduction}

In this digital age, smartphone and tablet apps have become must-haves for almost any modern business that aspires to reach and attract millennial customers [1]. Upon choices of digital device for selecting product and service, $70 \%$ of Indonesian people use mobile phone, while $15 \%$ uses desktop and another $15 \%$ use multiplatform [2]. It shows that mobile phones dominate the market as the option to search the product. Research by

Received (February 19, 2018), Review Result (April 27, 2018), Accepted (May 30, 2018)

* Corresponding Author 
Nielsen Company highlight that $85 \%$ of people aged 18 to 34 own smartphone [1]. As consumers have come to rely on mobile devices in more aspects of daily life, the customisable and refined experience of apps have led to their dominance within mobile consumption [2]. As smartphone and mobile phone become more powerful [3], thus the increase use of smartphones impact the development of mobile apps used daily by consumers to provide information or to make purchases of products and services [4].

Yahoo's Flurry Analytics shows that Indonesia people spend 90\% of their mobile time consumption in apps rather than in browser [2]. Suprisingly, Indonesian people spend more time consumption on apps rather than all people in the world. This is a key insight as companies decide whether to develop mobile apps, create mobile device specific apps, or restrict themselves to mobile optimised sites [2]. It said that majority of digital media consumption now take place in mobile application [2]. Millennials are even using apps for a wide range of services where $72 \%$ say they like the ability to purchase a company's product or service using mobile apps [1]. Mobile applications are running on a small hand hold mobile device which is moveable, easy to use and accessible from anywhere and any place [5]. Mobile application is easy, user friendly, inexpensive, downloadable and run able in most of the mobile phone including inexpensive and entry level phone [5]. Not only the mobile application has an impact for user but also it plays an important role in business [5]. Mobile applications have become an important platform for brands to interact with customers [6].

With the growing use of smartphone apps, business marketers are realizing the potential of branded apps as an effective marketing tool [4]. Understanding the customer purchase behavior is vital for any organization [7]. Customers tend to show purchase intention if they interact with branded apps [4]. Purchase intention is one of the final goals of marketing activity to achive purchase decision [8]. Mobile apps also increase the favorability of brand attitude and purchase intention [9]. Mobile apps adoption and continued use of the branded apps increase future spending [6]. With all these facts, company should prioritize launching mobile apps to communicate with their customers [6]. However, consumer preference for mobile apps vs mobile sites should also be thought through as part of mobile strategy [2].

The Hitwise Mobile Search elaborates the data on share of online searcher initiated on a mobile device by industry type on 2016 [2]. The results show top ten industry type search by consumers; entertainment $(42 \%)$, property (48\%), travel $(52 \%)$, automotive $(62 \%)$, lifestyle $(62 \%)$, news and media $(64 \%)$, sports $(68 \%)$, health $(68 \%)$, and food and beverage (72\%) [2]. Suprisingly, food and beverage industry hold the most share percentage people search on mobile device. With two facts described above; Indonesian people spent $90 \%$ on their mobile time consumption in apps and $72 \%$ people search food and beverage on mobile device, it is a must for food and beverage industry to be available in mobile device as well as mobile application.

Domino's Pizza Indonesia, as one of food and beverage industry, is the first fast food restaurant in Indonesia that launched its mobile application in August 2015 upon their seventh birthday and named as Domino's Pizza Indonesia mobile application. It can be downloaded for free in mobile operating system such as Android (Google Play Store) and iOS (Apple Store). One attribute that is often used in distinguishing good apps from bad ones are their ratings [10].

The main purpose of this paper is to determine the influence of Domino's Pizza mobile application on purchase intention. To achieve the main purpose, several research statements are highlight; (a) what is the Domino's Pizza mobile application quality rating, from the point of view of apps- user and non apps- user?, (b) do apps- user and non appsuser show different purchase intention?, and (c) to what extent Domino's Pizza mobile application influence the purchase intention. 


\section{Mobile Application}

\subsection{Branded Mobile Application}

Mobile application is easy, user- friendly, inexpensive, downloadable and run able in most of the mobile phone including inexpensive and entry level phone [5]. Most mobile interactions take place via mobile apps designed to fulfill specific user demands for shopping, entertainment, information, and social interaction. To achieve viability, the developers and publishers of mobile apps must create suitable business models [11]. The popularity of branded applications as a marketing tool is due to their high level of user engagement, enhancing the influence of advertising on consumers' attitudes toward the sponsoring brand [12].

Branded apps is a softwar that is downloaded in a mobile device that prominently displays a brand identity and heavy use the name of the apps and the appearance of a brand logo or icon throughout the user experience [9]. Business objectives of branded apps are communication, customer relationship management, sales, product innovation, and marketing research [13]. Branded apps aim to create completely new purchasing experiences and interaction models for users, with a whole set of capabilities including location awareness, context sensing, and product customization [13]. Branded apps can support open innovation by allowing users to generate new ideas for products [13]. Results showed that consumers have positive emotional responses to site visits when the visit is conducted on a mobile platform such as apps than other platforms [14]. There are five main reasons that made people stop from using apps; poor performance/ speed $(63 \%)$, high cost $(62 \%)$, security cost $(59 \%)$, poor design or layout $(49 \%)$, and less functionality compared to computer (35\%) [1].

\subsection{Domino's Pizza Indonesia Mobile Application}

In 2015, Domino's Pizza Indonesia under the PT Mitra Adiperkasa released its mobile application called as Domino's Pizza Indonesia mobile application with PT DOM PIZZA INDONESIA as the developer [15]. This application is only valid for ordering in Indonesia, currently serving Jakarta, Depok, Bekasi, Tangerang, Bogor, Bandung, Bali, Serang and Sukabumi [16]. The delivery promise of 30 minutes guarantee is applicable for all orders placed through this Mobile Application. After logging in, customers can do pizza tracker, browse the menu, register or order as a guest, select a carryout or delivery order, choose favorite pizza and place the order. Domino's Pizza Indonesia has nine features [16]; (a) Order favourite pizza, pasta, sides, desserts and drinks with easy navigation, (b) Order the latest Dominos Indonesia promotions and get the best deals, (c) Monitor the order progress with Domino's Pizza Tracker, (d) Find the nearest Domino's store location from the current location, (e) Find the address with a click of a button, (f) Identify the location by pin-drop address location, (g) Place an order to a future date and time (advanced time order), (h) Just one click to reorder favourite pizza, and (i) Sign in with Facebook account.

By creating mobile apps on all platforms, a responsive website, easy click ordering system and making pizza tracker available on smart watches, Domino's Pizza Indonesia is making it easier for the customers to order. Domino's Pizza Company is committed to being at the forefront of technology innovation. The way technology is evolving and the pace in which it is moving means company is always trying to come up with the next innovative idea and amazing technology to bring to the market. Domino's is always trying to think about the next thing that could make ordering quicker and easier for the customers. 


\subsection{Mobile Application Rating Scale (MARS)}

The MARS is the first app quality rating tool to provide a multidimensional measure of the app quality indicators of engagement, functionality, aesthetics, and information quality, as well as app subjective quality. The MARS star rating is likely to provide a more reliable measure of overall app quality, as it is rated following completion of the entire MARS. The MARS provides a multidimensional, reliable, and flexible app-quality rating scale for researchers, developers, and health-professionals [17]. The apps quality criteria were clustered into two quality scales; objectives quality and subjectives quality. Objectives quality consists of four dimensions; the engagement, functionality, aesthetics, information quality, of total 19 indicators, while subjective quality consists of four indicators with no dimension. Total of 23 indicators were scaled and calculate to get the apps quality rating [17].

Objectives quality consists of four dimensions. The first dimension of objectives quality rating is engagement. Engagement means that the apps is fun, interesting, customisable, interactive (sends alerts, messages, reminders, feedback, enables sharing), well-targeted to audience. Engagement consists of five indicators; (a) Entertainment: Is the app fun/entertaining to use? Does it use any strategies to increase engagement through entertainment? (b) Interest: Is the app interesting to use? Does it use any strategies to increase engagement by presenting its content in an interesting way?, (c) Customisation: Does it provide/retain all necessary settings/preferences for apps features (e.g., sound, content, notifications, etc.)?, (d) Interactivity: Does it allow user input, provide feedback, contain prompts (reminders, sharing options, notifications, etc.)? Note: these functions need to be customisable and not overwhelming in order to be perfect and (e) Target group: Is the app content (visual information, language, designs) appropriate for your target audience? [17].

The second dimension of objectives quality rating is functionality Functionality means that the apps is functioning, easy to learn, navigation, flow logic, and gestural design of app. Functionality consists of four indicators; (a) Performance: How accurately/ fast do the app features (functions) and components (buttons/ menus) work? (b) Ease of use: How easy is it to learn how to use the app; how clear are the menu labels/icons and instructions? (c) Navigation: Is moving between screens logical/ accurate/ appropriate/ uninterrupted; are all necessary screen links present? And (d) Gestural design: Are interactions (taps/ swipes/ pinches/ scrolls) consistent and intuitive across all components/ screens? [17].

The third dimension of objectives quality rating is aesthetics. Aesthetics cover apps graphic design, overall visual appeal, colour scheme, and stylistic consistency. Aesthetics consists of three indicators; (a) Layout: Is arrangement and size of buttons/ icons/ menus/ content on the screen appropriate or zoomable if needed? (b) Graphics: How high are the quality/ resolution of graphics used for buttons/ icons/ menus/ content? (c) Visual appeal: How good does the app look? [17].

The fourth dimension of objectives quality rating is information. Information contains high quality information such as text, feedback, measures, and references from a credible source. Information consists of seven indicators that can be customized based on the apps avaibility; (a) Accuracy of app description (in app store): Does app contain what is described? (b) Goals: Does app have specific, measurable and achievable goals (specified in app store description or within the app itself)? (c) Quality of information: Is app content corrected, well- written, and relevant to the goal/ topic of the app? (d) Quantity of information: Is the extent coverage within the scope of the app; and comprehensive but concise? (e) Visual information: Is visual explanation of concepts - through charts/ graphs/ images/ videos, etc. - clear, logical, correct? (f) Credibility: Does the app come from a legitimate source (specified in app store description or within the app itself)? (g) Evidence base: Has the app been trialled/ tested; must be verified by evidence (in published scientific literature)? [17]. Subjective quality consists of four indicators; (a) 
would you recommend this app to people who might benefit from it? (b) How many times do you think you would use this app in the next 12 months if it was relevant to you? (c) Would you pay for this app? (d) What is your overall star rating of the app?

$\boldsymbol{H}_{1 .}$ The mean value of apps user perceptions' on quality ratings of Domino's Pizza Indonesia mobile application is higher than the mean value of non apps-user perceptions'.

\subsection{Purchase Intention}

Intention is a sign and an indication of a person's willingness to perform the behavior, and it is an immediate antecedent of behavior [18]. Intention is also defined as an individual's readiness to perform a certain action. Intention directly precedes behavior. The intention incorporates attitude toward behavior, subjective norm, and perceived behavioral control [19]. A purchase intention is an individual's conscious plan to make an effort to purchase a brand [20]. Due to consumers' buying decision that is very complex, usually purchasing intention is related with consumers' behavior, perception and their attitude [21]. Consumer's attitude towards brand influences consumer's purchase intention [22]. Intention to buy may be referred as a reflection of real purchase behavior. The greater the purchase intention is, the greater a consumer's desire is to buy a product or service [23]. On the contrary, a lower willingness does not mean an absolute impossibility to buy [24]. Purchase intention and online shopping behavior indicate strong relationship [25]. It is speculated that behavior which leads to purchase is different for each customer. Some customers may purchase after gathering much information. Other customers may purchase long time after their last purchase. Viewing product pages has positive effects on purchase on average [26].

There are total 17 antecedents of customer purchase intention, categorized into two factors; consensus and non- consensus [7]. Non-consensus factors consist of promotion and adverstisement, convenience, motivation, consumer satisfaction, safety concern, customer loyalty, perceived usefulness and ease of use [7]. Consensus factors consist of ten indicators [7]. The first indicator is brand image. Brand image is an important cue during the process of consumers' purchase decision making [24]. The brand image is an important aspect towards purchase intention. It guides the consumers to consume more on the specific brand having a good brand image. Further, it helps consumers in taking a call on an important decision - that of ascertaining which brand is a more suitable option for them; also it induces the consumers to make purchase intentions [7]. There are positive and direct effects among brand image, perceived quality, perceived value, and purchase intention [24]. Brand image indeed increases investors' purchase intentions [24].

The second indicator is price. Price is one of a key factor in stirring up the purchase intentions of the consumers [27]. A reasonable price and a good general outlook of the products is a reason enough to trigger a high level satisfaction and confidence for the consumers to purchase the product [7]. The third indicator is perceived quality. Perceived quality shows a significant impact on consumer's purchase intention [28]. There is a strong relationship between consumers ' perceived quality, satisfaction, loyalty and buying intention for foodstuffs [29]. The higher perception of quality improves consumers' perceived value that strengthens consumers' purchase intention [30]. The fourth indicator is demographic. Of utmost significance are features such as age, gender and race (demographic) which have a bearing on the purchase intentions. The striking point is that consumers in different age groups have different choice behavior [7]. The fifth indicator is perceived value. Perceived value plays an important role in purchase or consumption decisions [24]. Perceived value is relevant to the emotional responses and consumption experiences of consumers, which can further influence the consumer's purchase behavior [30]. When other things remain unchanged, purchase intention is positively related to perceived value [28]. 
The sixth indicator is trust. In other words, if the trust or perceives a vendor's competence (ability), fairness (benevolence), and ethics (integrity) to be sufficient; consumers will develop the intention to purchase toward trustee. In essence, we can expect that an increase in trust will directly and positively have a bearing on the purchase intention [7]. Trust appeared to be significant predictor of intention to purchase online [31]. Trust in the online environment is particularly important [32]. The seventh indicator is attitude. In order of influence, attitude towards purchasing customized PC, followed by self-confidence, and subjective norm, have an influence on behavioral intention [7]. Attitudes towards e-deals and normative influence positively affect consumers' purchase intention towards e-deals [33]. Purchase intention associated positively with attitude [34]. Attitude and perceived price may influence consumers' purchase intention [21].

The eighth indicator is normative belief and self- efficacy. The individual's normative beliefs indicate that specific individuals or groups think that the individual should or should not perform the behavior [19]. Normative belief is one of subjectives norm determinants [19]. Self-efficacy defines consumer's ability to performance a task by motivating and constructing his/her attitude towards green purchasing intentions [35]. The ninth indicator is country of origin. The country of origin concept evolved into a more complex notion as global production operations became increasingly diverse and new market opportunities emerged [7]. The concept of country of origin involves the country where the brand originates or is manufactured [36]. Many researchers report that, consumers prefer products made by developed countries over those from less developed countries [36]. The tenth indicator is health consciousness. Health consciousness is known to predict attitudes, intention and purchase of organic food [7]. Health consciousness best describes those - consumers who are aware and concerned about their state of well-being and are motivated to not only enhance and or maintain their health and quality of life, but also safeguarding against ill-health through engagement in health behavior and remaining health conscious [7].

$\boldsymbol{H}_{2 .}$ Domino's Pizza Indonesia mobile apps- user has higher purchase intention mean value than non apps- user.

$\boldsymbol{H}_{3}$. The influence percentage of Mobile Application Rating Scales (MARS) towards purchase intention of Domino's Pizza Indonesia apps- user is higher than non apps- user

\section{Research Method}

This research use quantitative approach. Quantitave research is an approach for testing objective theories by examining the relationship among variable [37]. This method involves the processes of collecting, analyzing, interpreting, and writing the results [37]. There are two variables in this research; Domino's Pizza Indonesia mobile application and purchase intention. Primary data was obtained from survey using questionnaire. The questionnaire designed with closed-ended questions with optional given answer. Questionnaire consists of three sections.

The first section accumulated demographic of respondents in term of gender, age, occupation and domicile. The second section assessed about Domino's Pizza Indonesia mobile application quality rating that consists of 18 questions. The third section assessed about purchase intention that consists of 11 questions. The second section was measured on a five point scale (1-Inadequate, 2-Poor, 3-Acceptable, 4-Good, 5-Excellent) descriptors for these rating anchors were written for each item. The third section was measured on a five point scale from (1-Strongly disagree, 2-Disagree, 3-Somewhat agree, 4-Agree, 5-Strongly agree). Prior conducting the main survey, a pilot test for pre- testing purpose was conducted and distributed among 20 respondents on April 2017, consist of 10 respondents who have the apps installed in their mobile and 10 respondents who do not have the apps but acknowledge Domino's Pizza brand. App-quality ratings should be 
piloted and reviewed until an appropriate level of interrater reliability or consensus ratings are reached [17]. Refer to Table 1, Cronbach's Alpha value is ranging from 0.928 to 0.952. It is generally agreed that lower limit for Cronbach's Alpha is 0.70 although it may decreased to 0.6 in exploratory research [38].

With Cronbach's Alpha value of 0.928 for this study, meaning that all research questions are reliable. Tabel 1 also shows that all Corrected Item- Total correlation value is more than $r$ table value of 0.444. Data show to be valid by comparing value of corrected item-total correlation that all are higher than $r$ table. From the pilot study, all variables are valid and reliable.

Table 1. Validity and Reliability for Pilot Study

\begin{tabular}{|c|c|c|c|c|}
\hline No. & Indicators & $\begin{array}{l}\text { Corrected item- } \\
\text { total correlation }\end{array}$ & $\begin{array}{c}\text { Cronbach } \\
\text { Alpha } \\
\end{array}$ & Result \\
\hline 1 & Entertainment & .843 & .946 & Valid \& reliable \\
\hline 2 & Interest & .848 & .946 & Valid \& reliable \\
\hline 3 & Customization & .778 & .947 & Valid \& reliable \\
\hline 4 & Interactivity & .624 & .950 & Valid \& reliable \\
\hline 5 & Target group & .712 & .948 & Valid \& reliable \\
\hline 6 & Performance & .467 & .951 & Valid \& reliable \\
\hline 7 & Ease of use & .457 & .951 & Valid \& reliable \\
\hline 8 & Navigation & .669 & .949 & Valid \& reliable \\
\hline 9 & Gestural design & .798 & .947 & Valid \& reliable \\
\hline 10 & Layout & .738 & .948 & Valid \& reliable \\
\hline 11 & Graphics & .826 & .947 & Valid \& reliable \\
\hline 12 & Visual appeal & .746 & .948 & Valid \&reliable \\
\hline 13 & Accuracy of app description & .515 & .951 & Valid \& reliable \\
\hline 14 & Goals & .472 & .951 & Valid \& reliable \\
\hline 15 & Quality of information & .651 & .949 & Valid \& reliable \\
\hline 16 & Quantity of information & .515 & .951 & Valid \& reliable \\
\hline 17 & Visual information & .872 & .947 & Valid \& reliable \\
\hline 18 & Credibility & .909 & .945 & Valid \& reliable \\
\hline 19 & Recommendation & .717 & .949 & Valid \& reliable \\
\hline 20 & Frequency usage & .870 & .946 & Valid \& reliable \\
\hline 21 & Willingness to buy apps & .684 & .952 & Valid \& reliable \\
\hline 22 & Overall rating & .882 & .946 & Valid \& reliable \\
\hline 23 & Brand image & .895 & .930 & Valid \& reliable \\
\hline 24 & Price & .706 & .937 & Valid \& reliable \\
\hline 25 & Perceived quality- brand & .823 & .932 & Valid \& reliable \\
\hline 26 & Perceived quality- product & .851 & .931 & Valid \& reliable \\
\hline 27 & Perceived value & .871 & .930 & Valid \& reliable \\
\hline 28 & Trust & .894 & .929 & Valid \& reliable \\
\hline 29 & Attitude & .897 & .928 & Valid \& reliable \\
\hline 30 & Normative belief & .818 & .933 & Valid \& reliable \\
\hline
\end{tabular}

Thus, further survey was conducted on June 2017 and distributed to total 76 respondents. Respondents are divided into two categories. The first category is 38 respondents who have Domino's Pizza Indonesia mobile application in their mobile device. The second category is 38 respondents who do not have Domino's Pizza Indonesia mobile application in their mobile device but do acknowledge Domino's Pizza brand. Respondents were selected based on the criteria aside by the researcher, fox example either they have Domino's apps or not, with main criteria that they acknowledge Domino's brand.

To collect the primary data, web based survey and a face to face self administrative survey was conduct. Web-based surveys have emerged as an effective means of collecting data for academic research [11]. This method applied only to some of the first 
respondents' category. A face to face self administrative applied for second category of respondents. In order for this category able to answer the research question about Domino's Pizza Indonesia mobile apps, thus researcher use one to one approachment by showing the apps and let the respondents explored the entire apps feature within 10 to 15 minutes. Once the respondents already see all the features, then researcher gave the questionnaires to be filled up. This way, researcher ensured that the respondents filled up the questionnaire by knowing the content about the apps. All statistical procedures were conducted using SPSS ver 23. The data obtain from questionnaire, and then analyze using descriptive statistic analysis, comparing mean analysis, correlation analysis and regression analysis with total of three hypotheses.

\section{Results and Discussion}

\subsection{Demographic Respondents}

Table 2 shows the demographics of the respondents. The demographic profile shows that the majority of respondents is male $(57.9 \%)$, student $(68.4 \%)$, age below or equal to 22 years old $(59.2 \%)$, and domicile in Jakarta (78.9\%). As explained earlier that respondents are divided into two categories; apps- user and non apps-user, and both show similar majority.

Table 2. Profile of Respondents

\begin{tabular}{llcccccc}
\hline \multirow{2}{*}{ Category } & \multicolumn{1}{c}{ Items } & \multicolumn{2}{c}{ All } & \multicolumn{2}{c}{ Apps-user } & \multicolumn{2}{c}{ Non apps-user } \\
\cline { 3 - 8 } & & $n$ & $\%$ & $n$ & $\%$ & $n$ & $\%$ \\
\hline \multirow{2}{*}{ Gender } & Male & 44 & $57.9 \%$ & 19 & $50 \%$ & 25 & $65.8 \%$ \\
& Female & 32 & $42.1 \%$ & 19 & $50 \%$ & 13 & $34.3 \%$ \\
Age & $\leq 22$ years old & 45 & $59.2 \%$ & 23 & $60.5 \%$ & 22 & $57.9 \%$ \\
\multirow{3}{*}{ Occupation } & 23- 30 years old & 31 & $40.8 \%$ & 15 & $39.5 \%$ & 16 & $42.1 \%$ \\
& Student & 52 & $68.4 \%$ & 29 & $76.3 \%$ & 23 & $60.5 \%$ \\
& Employee & 15 & $19.7 \%$ & 5 & $13.2 \%$ & 10 & $26.3 \%$ \\
& Entrepreneur & 8 & $10.5 \%$ & 4 & $10.5 \%$ & 4 & $10.5 \%$ \\
\multirow{3}{*}{ Domicile } & Others & 1 & $1.4 \%$ & - & - & 1 & $2.7 \%$ \\
& Jakarta & 60 & $78.9 \%$ & 29 & $76.3 \%$ & 31 & $81.6 \%$ \\
& Outside Jakarta & 16 & $21.1 \%$ & 9 & $23.7 \%$ & 7 & $18.4 \%$ \\
\hline
\end{tabular}

\subsection{Domino's Pizza Indonesia Mobile Application Quality Scale}

Table 3 lists the means and standard deviations of Domino's Pizza Indonesia mobile application. On average, respondents responded positively (as overall average is greater than 3). Furthermore, the table shows that apps- user has had more value than non- apps user, both on objective quality and subjective quality. On engagement variable, Domino's Pizza Indonesia Mobile Application is fun enough to entertain user for a brief time (for less than 5 minutes). The app is neither interesting nor uninteresting, but it would engage user for a brief time (for less than 5 minutes). The app allows basic customisation to function adequately which enables basic interactive features on the app function adequately. The app is acceptable for users but not targeted. On functionality variable, Domino's Pizza Indonesia Mobile Application works overall but there were some technical problems which need to be fixed. The app is easy to learn because it has clear instruction within it. The moving between screens and screen link are usable after some time or some effort. The interaction within apps is quite good with some inconsistencies or confusing elements. On aesthetics variable, the overall layout, including arrangement and size of content is satisfactory, with few problems with selecting/ locating/ seeing/ reading items or with minor screen-size problems. The resolution of graphics used on the app has good quality and visual design. The app look has visual appeal on average. On 
information variable, Domino's Pizza Indonesia Mobile Application contains some of the described components or functions. The app has clear goals which may be achievable. The app content is relevant to the goal/ topic of app, has appropriate and correct content, well-written, coherent and appears correct. The extent coverage within the scope of the app is fine but not comprehensive or concise. The visual information is mostly clear, logical and correct with negligible issues. The app is credible since it is made by Domino's Pizza Indonesia as its commercial business.

On subjective quality, the respondents may recommend Domino's Pizza Indonesia Mobile Application to several people. Respondents would use the app for 3-10 times in the next 12 months. However, they do not prefer to buy this app. Overall, the star rating for the app is average (3-star-rating). According to objective quality of app- user, the engagement variable has the lowest mean score among other variables (3.67 which means good enough). Domino's Pizza Indonesia has not maximized the push notifications as big advantage of mobile application features to engage with its users and encourage them to reuse the app, such as invite them to reuse app by pop-up promotion message. Therefore, there was some apps- user who uninstalled the app after some time usage because they did not find any other benefit gained from the app compare to Domino's Pizza Indonesia website which provides same function with the mobile apps. On the other hand, the highest mean score is 3.98 for information variable which means the information provided on the app is informative for the apps- user.

According to objective quality of non- apps user, engagement variable has the lowest mean score among other variables (3.64) which means good enough. On first try, the monotous design (layout, color and font type) of the app makes non- app user feel bored to reuse the app again. On the other hand, due to monotous and simple design, it makes first-timer easy to learn how to use the app which makes the functionality variable reach the highest variable mean score.

$\boldsymbol{H}_{1 .}$ The mean value of apps user perceptions' on quality ratings of Domino's Pizza Indonesia mobile application is higher than the mean value of non apps-user perceptions'.

Refer to Table 3 where apps- user mean value of objectives quality is 3.88 while non apps- user is 3.73 , shows that the mean value of apps user perceptions' on quality ratings of Domino's Pizza Indonesia mobile application is higher than the mean value of non apps-user perceptions', thus $\mathrm{H}_{1}$ is accepted.

Table 3. Mobile Application Rating Scale Descriptive Statistic

\begin{tabular}{lcccccc}
\hline \multirow{2}{*}{ MARS Indicators } & \multicolumn{3}{c}{ All } & \multicolumn{2}{c}{ Apps-user } & \multicolumn{2}{c}{ Non- apps user } \\
\cline { 2 - 7 } Engagement & Mean & SD & Mean & SD & Mean & SD \\
Entertainment & $\mathbf{3 . 6 5}$ & & $\mathbf{3 . 6 7}$ & & $\mathbf{3 . 6 4}$ & \\
Interest & 3.75 & .896 & 3.87 & .906 & 3.63 & .883 \\
Customization & 3.75 & .954 & 3.76 & .971 & 3.74 & .950 \\
Interactivity & 3.67 & .900 & 3.61 & 1.028 & 3.74 & .760 \\
Target group & 3.36 & 1.029 & 3.29 & 1.088 & 3.42 & .976 \\
Functionality & 3.74 & .929 & 3.79 & .935 & 3.68 & .933 \\
Performance & $\mathbf{3 . 8 7}$ & & $\mathbf{3 . 9 4}$ & & $\mathbf{3 . 8 0}$ & \\
Ease of use & 3.93 & .789 & 4.05 & .804 & 3.82 & .766 \\
Navigation & 4.03 & .816 & 4.00 & .805 & 4.05 & .837 \\
Gestural design & 3.70 & 1.007 & 3.74 & .978 & 3.66 & 1.047 \\
Aesthetics & 3.83 & .855 & 3.97 & .788 & 3.68 & .904 \\
Layout & $\mathbf{3 . 8 4}$ & & $\mathbf{3 . 9 6}$ & & $\mathbf{3 . 7 2}$ & \\
Graphics & 3.84 & .767 & 3.95 & .804 & 3.74 & .724 \\
Visual appeal & 3.91 & .769 & 4.00 & .805 & 3.82 & .730 \\
& 3.76 & .877 & 3.92 & .941 & 3.61 & .790 \\
\hline
\end{tabular}




\begin{tabular}{lcccccc}
\hline Information & $\mathbf{3 . 8 8}$ & & $\mathbf{3 . 9 8}$ & & $\mathbf{3 . 7 7}$ & \\
Accuracy of app description & 3.93 & .884 & 4.11 & .924 & 3.76 & .820 \\
Goals & 3.79 & .789 & 4.03 & .788 & 3.55 & .724 \\
Quality of information & 3.97 & .765 & 4.05 & .769 & 3.89 & .764 \\
Quantity of information & 3.86 & .795 & 3.95 & .804 & 3.76 & .786 \\
Visual information & 3.97 & .800 & 3.97 & .822 & 3.97 & .788 \\
Credibility & 3.76 & .892 & 3.82 & .926 & 3.71 & .867 \\
Total Objectives Quality & & & & & & \\
(Equal to total apps quality) & $\mathbf{3 . 8 1}$ & & $\mathbf{3 . 8 8}$ & & & \\
Subjective & & & & & & \\
Would you recommend this app? & 3.63 & 1.130 & 3.76 & 1.149 & 3.50 & 1.109 \\
How many times do you think you would use & 3.37 & 1.018 & 3.53 & 1.006 & 3.21 & 1.018 \\
this app? & & & & & & \\
Would you pay for this app? & 2.18 & 1.671 & 2.47 & 1.842 & 1.89 & 1.448 \\
What is your overall star rating of the app? & 3.53 & 1.000 & 3.53 & 1.059 & 3.53 & .951 \\
Total Subjectives Quality & $\mathbf{3 . 1 8}$ & & $\mathbf{3 . 3 2}$ & & $\mathbf{3 . 0 3}$ & \\
\hline
\end{tabular}

\subsection{Purchase Intention}

Table 4 lists the means and standard deviations of purchase intention. On average, respondents responded positively (as overall average is greater than 3). Furthermore, the table shows that apps-user has more purchase intention than non-user mobile apps. From table 4, the conclusion is that Domino's Pizza Indonesia has a good brand image on public as it never gets involved in any bad public issues. The price list of Domino's Pizza Indonesia are quite good, it provides consumers with various range of price for every products listed on the menu. The brand quality is good and the product quality is good enough, Domino's Pizza Indonesia has been performing good products and services for its consumers. Perceived value is good enough as Domino's Pizza Indonesia provides good deals for consumers from its products and promotions. Consumers' trust towards Domino's Pizza Indonesia's products and services are good due to consistency of providing its products and services.

Table 4. Purchase Intention Descriptive Statistic

\begin{tabular}{|c|c|c|c|c|c|c|}
\hline \multirow{2}{*}{ Purcase Intentions Indicators } & \multicolumn{2}{|c|}{ All } & \multicolumn{2}{|c|}{ Apps-user } & \multicolumn{2}{|c|}{ Non- apps user } \\
\hline & Mean & $\mathrm{SD}$ & Mean & SD & Mean & SD \\
\hline Brand image & 4.11 & .793 & 4.34 & .708 & 3.87 & .811 \\
\hline Price & 3.87 & .789 & 4.00 & .658 & 3.74 & .891 \\
\hline Perceived quality- brand & 4.04 & .756 & 4.32 & .620 & 3.76 & .786 \\
\hline Perceived quality- product & 3.66 & .793 & 3.89 & .831 & 3.42 & .683 \\
\hline Perceived value & 3.75 & .866 & 3.95 & .769 & 3.55 & .921 \\
\hline Trust & 4.00 & .849 & 4.26 & .685 & 3.74 & .921 \\
\hline Attitude & 3.96 & .855 & 4.21 & .664 & 3.71 & .956 \\
\hline Normative belief & 3.75 & 1.047 & 3.84 & 1.053 & 3.66 & 1.047 \\
\hline Self- efficacy & 4.05 & .937 & 4.39 & .679 & 3.71 & 1.037 \\
\hline Country of origin & 2.87 & 1.247 & 3.16 & 1.197 & 2.58 & 1.244 \\
\hline Health consciousness & 3.07 & .971 & 3.13 & .991 & 3.00 & .959 \\
\hline Total Puchase Intention mean & 3.74 & & 3.95 & & 3.52 & \\
\hline
\end{tabular}

In addition, social environment influences consumers to purchase Domino's Pizza Indonesia's products. Consumers are confident enough to be able to purchase products and services from Domino's Pizza Indonesia due to various choices of products and promotions. Country of origin of Domino's Pizza (United States) does not influence the consumers' purchase intentions since people in developing country (Indonesia) is more pay attention to price and received quality, they do not really pay attention to the origin country of the producer. Health consciousness of consumers towards Domino's Pizza 
Indonesia's products is good enough since its products are healthier than other fast food restaurants' products since pizza products are fresh-baked and contains various toppings to fulfill body's nutrition.

Apps-user is more familiar to Domino's Pizza Indonesia's brand rather than non- apps user. Domino's Pizza Indonesia has good brand image in apps- users' eyes, which encourages apps- user downloaded Domino's Pizza Indonesia's app on their smartphones. As the brand image is good and it builds consumers' trust, apps- user is more willing to purchase the products and services of Domino's Pizza Indonesia.

$\boldsymbol{H}_{2 .}$ Domino's Pizza Indonesia mobile apps- user has higher purchase intention mean value than non apps- user.

Refer to Table 4 where apps- user mean value of purchase intention is 3.95 while non apps- user is 3.52 , shows purchase intention of apps- user is higher mean value than non apps- user, thus $\mathrm{H}_{2}$ is accepted.

\subsection{MARS Towards Purchase Intention}

\subsubsection{MARS Simultantly Towards Purchase Intention}

Table 5 shows correlation and regression value for Domino's Pizza Indonesia mobile application towards purchase intention for all 76 respondents, despite the respondent have or do not have the apps installed in their mobile. The results show coefficient value 0.683 , meaning that Domino's Pizza Indonesia mobile application has strong correlation with purchase intention. Meanwhile, $\mathrm{R}$ square value 0.467 meaning that Domino's Pizza Indonesia mobile application influences purchase intention as $46.7 \%$.

Table 5. Model Summary I

\begin{tabular}{|l|l|l|l|l|}
\hline \multicolumn{5}{|c|}{ Model Summary } \\
\hline Model & $\mathrm{R}$ & R Square & $\begin{array}{l}\text { Adjusted } \\
\text { Square }\end{array}$ & $\begin{array}{l}\text { Std. Error of the } \\
\text { Estimate }\end{array}$ \\
\hline 1 & $.683^{\mathrm{a}}$ & .467 & .460 & 4.973 \\
\hline
\end{tabular}

a. Predictors: (Constant), Objective Quality

\subsubsection{MARS Apps- User and Non Apps- User Towards Purchase Intention}

Table 6 shows correlation and regression value for Domino's Pizza Indonesia mobile application for apps- user towards purchase intention. The results show coefficient value 0.688, meaning that Domino's Pizza Indonesia mobile application has strong correlation with purchase intention in the point of view of apps- user. Meanwhile, $\mathrm{R}$ square value 0.474 meaning that Domino's Pizza Indonesia mobile application influences purchase intention for apps- user as $47.4 \%$.

Table 6. Model Summary apps- user

\begin{tabular}{|l|l|l|l|l|}
\hline \multicolumn{5}{|c|}{ Model Summary } \\
\hline Model & $\mathrm{R}$ & R Square & $\begin{array}{l}\text { Adjusted } \\
\text { Square }\end{array}$ & $\begin{array}{l}\text { Std. Error of the } \\
\text { Estimate }\end{array}$ \\
\hline 1 & $.688^{\mathrm{a}}$ & .474 & .459 & 3.961 \\
\hline
\end{tabular}

a. Predictors: (Constant), Objective Quality 
Table 7. Model Summary non apps- user

\begin{tabular}{|l|l|l|l|l|}
\hline \multicolumn{5}{|c|}{ Model Summary } \\
\hline Model & $\mathrm{R}$ & R Square & $\begin{array}{l}\text { Adjusted } \\
\text { Square }\end{array}$ & $\begin{array}{l}\text { Std. Error of the } \\
\text { Estimate }\end{array}$ \\
\hline 1 & $.697^{\mathrm{a}}$ & .486 & .472 & 5.247 \\
\hline
\end{tabular}

a. Predictors: (Constant), Objective Quality

Table 7 shows correlation and regression value of Domino's Pizza Indonesia mobile application for non apps- user towards purchase intention. The results show coefficient value 0.697, meaning that Domino's Pizza Indonesia mobile application has strong correlation with purchase intention in the point of view of apps- user. Meanwhile, $\mathrm{R}$ square value 0.486 meaning that Domino's Pizza Indonesia mobile application influences purchase intention for non apps- user as $48.6 \%$.

In further observations, it is found that even though the overall Domino's Pizza Indonesia mobile application looked nice for both app- user and non- app user, but there were some features worked improperly while ordering products which had been experienced by app- user. On the other hand, non- app user who only tried the app did not find out the misfunction features. Therefore, due to bad experience of the app experienced by app- user, the purchase intention of app- user is slightly lower than non- app user.

$\boldsymbol{H}_{3 .}$ The influence percentage of Mobile Application Rating Scales (MARS) towards purchase intention of Domino's Pizza Indonesia apps- user is higher than non apps- user

Refer to Table 6 and Table 7 where $\mathrm{R}$ square value of apps- user is 0.474 while non apps- user is 0.486, shows that the influence percentage of Mobile Application Rating Scales (MARS) towards purchase intention of Domino's Pizza Indonesia apps- user is lower than non apps- user, thus $\mathrm{H}_{3}$ is rejected.

\subsection{Discussion}

There are three research questions will be answered. The first question is "what is the Domino's Pizza mobile application quality rating, from the point of view of apps user and non apps user?" Refer to MARS rating scale, Domino's Pizza Indonesia shows good quality of mean value 3.81 where ' 3 ' means acceptable and ' 4 ' means good. People with apps- user show mean value 3.88, while people non apps- user show means value 3.73. This result indicates that although people have no Domino's Pizza Indonesia mobile apps in their mobile, they still consider the quality as good. It can be summarized that Domino's Pizza Indonesia mobile application is not excellent in the point of view of customer. There are still many aspects that consider poor by both apps- user and non apps- user, especially related to engagement. It means people consider Domino's Pizza Indonesia mobile apps fun enough to entertain for only a brief time, less interesting to use, and unable to provide input or feedback for consumer. However, the strongest aspect of Domino's Pizza Indonesia mobile application in the point of view of consumer is different; apps- user consider that information quality is the best, while non apps- user consider functionality as the best one.

The second question is "do apps- user and non apps- user show different purchase intention?" People with apps- user show purchase intention mean value 3.95, while people non apps- user show purchase intention means value 3.52. This result indicates that people who have branded apps installed in their mobile have higher intention to purchase than those who do not. Purchase intention may have a positive influence on actual online purchasing [39]. Thus, it is important for Domino's Pizza Indonesia to ensure that all their branded apps- user is not only have intention to purchase, but eventually become an actual purchase stage. 
The third question is "to what extent Domino's Pizza mobile application influence the purchase intention". Apps- user purchase intention is influenced $47.4 \%$ by mobile application, while non apps- user purchase intention is influenced $48.6 \%$ by mobile application. This result indicates that company must consider all the potential market, especially those who acknowledge the brand but do not install the apps as they tend to be more influenced in their intention to purchase rather than those who already install the branded apps. This is a huge opportunity for Domino's Pizza Indonesia to strengthen their strategy to grab broaden market for people who are not their branded apps- user. There is an interesting finding that comes from the survey. The data shows that the mean score of trust among the apps-user is 4.26 while the non apps-user is only 3.74. This may refer to the fact that the consumers who installed the Domino's Pizza Mobile Application in their mobile has trusted the brand and more likely to purchase the product.

Oracle Corporation said that the best apps are intuitive and reliable, and are developed with a view of who will ultimately be using them; consumers, employees, and business partners will all expect a very different experience from their applications [1]. Branded apps need to be likeable, useful, pleasant and good to encourage their use [4]. Good mobile apps are aligned with different levels of user motivations and should engage them passionately [13]. Thus, for Domino's Pizza Indonesia mobile apps to be the best, it has to be likeable, useful, intuitive and reliable by considering who the users are. Domino's Pizza Indonesia must ensure to always engage with the user. This research reveals that branded mobile application has strong relationship with purchase intention, despite whether people install the mobile application or not. However, purchase intention is likely influenced more by branded mobile application non apps- user rather than the apps- user itself.

\section{Conclusions and Recommendations}

This study has determined Domino's Pizza Indonesia mobile application on purchase intention, thus three research questions will be answered. Despite of the interesting findings, this study has some limitations. The first limitation is the number of respondents that participated in the survey. The second limitation is the demographic of the respondents which were quite homogeneous, dominated by students and the age range are $\leq 22$ years old and 23 - 30 years old. More number of respondents with more heterogeneous profile may give more insights to the study. In order to maximize Domino's Pizza Indonesia mobile apps quality, management must ensure that the apps is not payable in the future, enhance interactive feature, add engagement program that encourage people to purchase through mobile application, and maximize push notification feature. Branded apps must comply with product personalization, share with external and social networks [13]. Apps providers should incorporate community and forum functions to encourage users to share their social lives and opinions, and thus prompt them to use the app more frequently and for longer periods [11]. However, all efforts for optimizing the mobile apps quality must be in line with the efforts to keep the customers' trust by continuing giving good services. Good services may result in satisfaction and in the end will enhance the purchase intention of the apps-user as well as the non apps-user. Further study can be conduct by broaden other fast food branded apps such as KFC Indonesia, McDonald's Indonesia and HokBen Indonesia using the same rating measurement which is MARS, and involve wider respondents.

\section{References}

[1] Oracle Corporation, "Millennials and mobility: how businesses can tap into the app generation", Oracle Corporation, CA- USA, (2014).

[2] D. Chaffey, "Smart Insight", 01 March 2017. [Online]. Available: http://www.smartinsights.com/mobile-marketing/mobile-marketing-analytics/mobile-marketingstatistics/. [Accessed August 2017]. 
[3] K. Curran and C. George, "The Future of Web and Mobile Game Development", International Journal of Cloud Computing and Services Science, vol. 1, no. 1, p. 25-34, (2012).

[4] V. A. Seitz and N. M. Aldebasi, "The Effectiveness of Branded Mobile Apps On User'S Brand Attitudes and Purchase Intentions", Review of Economic and Business Studies, vol. 9, no. 1, pp. 141154, (2016).

[5] R. Islam, R. Islam and T. A. Mazumder, "Mobile Application and Its Global Impact", International Journal of Engineering \& Technology IJET-IJENS, vol. 10, no. 6, (2010), pp. 104-112.

[6] S. J. Kim, R. J.-H. Wang and E. C. Malthouse, "The Effects of Adopting and Using a Brand's Mobile Application on Customers' Subsequent Purchase Behavior", Journal of Interactive Marketing, vol. 31, (2015), pp. 28-41.

[7] S. Pandey and S. Srivastava, "Antecedents of Customer Purchase Intention", IOSR Journal of Business and Management, vol. 18, no. 10, (2016), pp. 55-82.

[8] M. A. Karman, "The Impact of Social Media Marketing on Brand Equity toward the Purchase Intention of Starbucks Indonesia”, iBuss Management, vol. 3, no. 2, (2015), pp. 77-88.

[9] S. Bellman, R. F. Potter, S. Treleaven-Hassard, J. A. Robinson and D. Varan, "The Effectiveness of Branded Mobile Phone Apps”, Journal of Interactive Marketing, vol. 25, no. 4, (2011), pp. 191-200.

[10] M. Kuehnhausen and V. S. Frost, "Trusting smartphone Apps? To install or not to install, that is the question”, IEEE International Multi-Disciplinary Conference, San Diego, (2013).

[11] C.-L. Hsu and J. C.-C. Lin, "Effect of perceived value and social influences on mobile app stickiness and in-app purchase intention", Technological Forecasting \& Social Change, (2016), pp. 42-53.

[12] G. Hutton and S. Rodnick, "Smartphone opens up new opportunities for smart marketing", Admap, vol. 44, no. 11, (2009), pp. 22-44.

[13] Z. Zhao and C. Balague, "Designing branded mobile apps: Fundamentals and recommendations", Business Horizons, vol. 58, (2015), pp. 305-315.

[14] E. McRae, J. Carrabis, S. Carrabis and S. Hamel, "Want to be Loved? Go Mobile", International Journal of Mobile Marketing, vol. 8, no. 2, (2013), pp. 55-66.

[15] iTunes Apple, “iTunes Apple", [Online]. Available: https://itunes.apple.com/id/app/dominos-pizzaindonesia/id894487160? $\mathrm{mt}=8$, (2017).

[16] Google Play, "Google Play," 2017. [Online]. Available: https://play.google.com/store/apps/details?id=com.phonegap.dominos\&hl=en.

[17] S. R. Stoyanov, L. Hides, D. J. Kavanagh, O. Zelenko, D. Tjondronegoro and M. Mani, "Mobile App Rating Scale: A New Tool for Assessing the Quality of Health Mobile Apps", JMIR mHealth uHealth, vol. 3, no. 1, (2015).

[18] T. S. Al-Nahdi, S. A. Habib, A. H. Abu Bakar, M. S. Bahklah, O. H. Ghazzawi and H. A. Al-Attas, "The Effect of Attitude, Dimensions of Subjective Norm, and Perceived Behavior Control, on the Intention to Purchase Real Estate in Saudi Arabia”, International Journal of Marketing Studies, vol. 7, no. 5, (2015) September 29, pp. 120-131.

[19] I. Ajzen, "Perceived behavioral control, self-efficacy, locus of control, and the theory of planned behaviour", Journal of Applied Social Psychology, vol. 32, no. 4, (2002), pp. 665-683.

[20] N. Spears and S. N. Singh, "Measuring Attitude toward the Brand and Purchase Intentions", Journal of Current Issues \& Research in Advertising, vol. 26, no. 2, (2004), pp. 53-66.

[21] S. N. Jaafar, P. E. Lalp and M. M. Naba, "Consumers' Perception, Attitudes and Purchase Intention towards Private Label Food Product in Malaysia", Asian Journal of Business and Management Sciences, vol. 2, no. 8, (2013), pp. 73-90.

[22] S. K. Kaushal and R. Kumar, "Influence of Attitude Towards Advertisement on Purchase Intention:Exploring the Mediating Role of Attitude Towards Brand Using SEM Approach", The IUP Journal of Marketing Management, vol. XV, no. 4, (2016), pp. 44-59.

[23] L. Schiffman and L. Kanuk, Consumer Behavior, New Jersey: Prentice Hall, (2000).

[24] Y.-. H. Wang and C.-. F. Tsai, "The Relationship Between Brand Image and Purchase Intention: Evidence From Award Winning Mutual Funds", The International Journal of Business and Finance Research, vol. 8, no. 2, (2014), pp. 27-40.

[25] Y. J. Lim, A. Osman, S. N. Salahuddin, A. R. Romle and S. Abdullah, "Factors Influencing Online Shopping Behavior: The Mediating Role of Purchase Intention", Procedia Economics and Finance, vol. 35, (2016), pp. 401-410.

[26] S. Sato and Y. Asahi, "A Daily-level Purchasing Model at an E-commerce Site", International Journal of Electrical and Computer Engineering, vol. 2, no. 6, (2012), pp. 831-839.

[27] P. Kotler and K. L. Keller, "Marketing Management", Englewood Cliffs: Prentice Hall, (2009).

[28] C. J. Yee, N. C. San and C. H. Khoon, "Consumers' Perceived Quality, Perceived Value and Perceived Risk Towards Purchase Decision on Automobile", American Journal of Economics and Business Administ, vol. 3, no. 1, (2011), pp. 47-57.

[29] S. O. Olsen, "The Comparative Evaluation and the Relationship between Quality, Satisfaction, and Repurchase Loyalty", Journal of the Academy of Marketing Science, vol. 30, no. 3, (2002), pp. 240-249.

[30] J. F. Petrick, "First Timers' and Repeaters' Perceived Value", Journal of Travel Research, vol. 43, (2004), pp. 29-38. 
[31] A. Jamaludin and F. Ahmad, "Investigating the Relationship between Trust and Intention to Purchase Online", Business and Management Horizons, vol. 1, no. 1, (2013).

[32] A. Leeraphong and A. Mardjo, "Trust and Risk in Purchase Intention through Online Social Network: A Focus Group Study of Facebook in Thailand”, Journal of Economic, Business and Management, vol. 1, no. 4, (2013), pp. 314-319.

[33] I. Cheah, I. Phau and J. Liang, "Factors influencing consumers' attitudes and purchase intentions of edeals", Marketing Intelligence \& Planning, vol. 33, no. 5, (2015), pp. 763-783.

[34] Y. Hung, T. M. de Kok and W. Verbeke, "Consumer attitude and purchase intention towards processed meat products with natural compounds and a reduced level of nitrite", Meat Science, vol. 121, (2016), pp. 119-126.

[35] N. Sharma and R. Dayal, "Drivers of Green Purchase Intentions: Green Self-Efficacy and Perceived Consumer Effectiveness", Global Journal of Enterprise Information System, vol. 8, no. 3, (2016) September.

[36] J. Ha-Brookshire and S.-. H. Yoon, "Country of origin factors influencing US consumers' perceived price for multinational products", Journal of Consumer Marketing, vol. 29, no. 6, (2012), pp. 445-454

[37] J. W. Creswell, "Research Design: Qualitative, Quantitative, and Mixed Methods Approaches", California, USA: SAGE Publication, (2013).

[38] J. H. Hair, W. C. Black, B. J. Babin and R. E. Anderson, "Multivariate Data Analysis", New Jersey: Pearson Education, (2010).

[39] N. A. Jamil and N. K. Mat, "To Investigate the Drivers of Online Purchasing Behaviour in Malaysia Based On Theory of Planned Behaviour (Tpb): A Structural Equation Modeling (Sem) Approach”, in International Conference on Management (ICM 2011), (2011).

[40] T. Hong and E. Kim, "Segmentating Customers in Online Stores from Factors that Affect the Customer's Intention to Purchase", Expert Systems with Applications, vol. 39, no. 2, (2012) February 1, pp. 383388.

[41] I. Alnawas and F. Aburub, "The effect of benefits generated from interacting with branded mobile apps on consumer satisfaction and purchase intentions", Journal of Retailing and Consumer Services, vol. 31, (2016), pp. 313-322. 
International Journal of Advanced Science and Technology

Vol.117 (2018) 